\title{
O Uso de Programação no Design de Padrões
}

\author{
The Use of Programming in Pattern Design
}

\author{
LARANJEIRA, Mariana A.; Mestranda; UNESP, Bauru \\ marilaranjeira@faac.unesp.br \\ MARAR, João Fernando; Doutor; UNESP, Bauru \\ fermarar@fc.unesp.br
}

\section{Resumo}

Como uma área de pesquisa e desenvolvimento entre designers, o Design de Superfície vem crescendo e se tornando mais popular nos últimos anos. A emergência e expansão desse campo amplia a pesquisa científica e acadêmica que desdobra um novo caminho de expressões artísticas e processos inovadores a serem explorados para a criação de padrões. Para esten der o conhecimento e ampliar o potencial de aplicação, é relevante que se determinem métodos, materiais e as implicações de uma perspectiva de projeto na criação de superfícies. Nesta extensão, esta pesquisa contribui ao conectar a referida disciplina com a ciência da computação e a programação, identificando métodos algorítmicos e o uso do software Processing para a criação de padronagens estáticas ou interativas. Assim, este artigo discute o design generativo e os métodos consequentes para criar abordagens que podem melhorar as propriedades da superfície e gerar inovação através da complexidade.

Palavras Chave: design de superfície; padronagem; generativo; Processing.

\begin{abstract}
Surface Design has been growing and becoming more popular in the latest years, as an area for research and development among designers. The emergency and expansion of this field increases scientific and academic research that unfolds a new path of artistic expressions and innovative processes to be explored for the creation of patterns. To extend the knowledge, and to widen potential applications, it is relevant to determine methods, materials and the implications of a design perspective in the creation of surfaces. At this extend, this research contributes by connecting this referred discipline with computer science and programming, identifying algorithmic methods along with the use of the software Processing for static or interactive patterns. Therefore, this paper discusses generative design and applied methods for creating approaches that can enhance surface properties and generate innovation through complexity.
\end{abstract}

Keywords: surface design; pattern; generative; Processing. 


\section{Introdução}

O design de superfícies complexas e interativas emerge exponencialmente com o desenvolvimento da ciência da computação e a democratização das linguagens de programação. Assim, por meio de algoritmos programados se torna possível o surgimento de códigos com alta complexidade de lógica e matemática que resultem em superfícies bidimensionais e tridimensionais com propriedades estéticas diferenciadas.

A tendência da absorção da complexidade influencia os processos de projeto em ambiente digital e permite a visualização da forma, não apenas como item independente, mas como elemento inserido em todo um sistema de interação e organização. Alexenberg (2011, p.47) afirma que "a lógica formal dos algoritmos oferece infinitas possibilidades criativas, decorrências indescritíveis da atemporalidade e o desdobramento de metáforas escondidas nas profundidades insondáveis das estruturas de espaço e tempo".

Nesse contexto, a computação influencia no processo do design de maneira que um algoritmo tem a capacidade de gerar uma infinidade de soluções diferenciadas para um único problema. No caso de algoritmos para o desenvolvimento da forma, essas soluções tendem a ser de ordem geométrica e estética, mas podem ser também de ordem estrutural e física dependendo da aplicação da superfície criada. Entretanto, mais do que a procura por soluções inovadoras, o uso da computação e de linguagens de programação no design é uma prática cultural que busca a produção de sentidos por meio da tecnologia.

O software Processing, por ser uma linguagem de programação alternativa voltada a representações visuais e criação de imagens, foi a ferramenta criativa escolhida nesta pesquisa para a apresentação de algoritmos no design de superfície, mais especificamente na criação de padrões de repetição. Essa tecnologia criada em 2001 no MIT (Massachusetts Institute of Technology) por Casey Reas e Ben Fry, possibilita novas formas de expressão por meio de códigos escritos e incentiva a abertura da informação e colaboração artística por ser um software livre.

O Processing é um programa que pode ser definido como "um ambiente que permite a criação de narrativas interativas, jogos, simulações e produções computacionais que são desenvolvidas em linguagem de programação e que são compartilhadas em uma comunidade online" (BOZOLAN, 2016, p.43). O seu sucesso como linguagem de programação no meio das artes interativas se deve à sua simplicidade, quando comparada a outras linguagens, e ao seu aspecto livre e colaborativo, que permitiu o surgimento de uma grande comunidade online de artistasprogramadores que compartilham conhecimentos e colaboram entre si (MELLO, 2015).

Buscando entender o papel de linguagens de programação como o Processing no processo criativo do design de superfícies, a pesquisa aqui reportada analisou o desenvolvimento de algoritmos específicos para a construção de padrões de repetição que resultem em padronagens, sejam estas digitais ou impressas, estáticas ou interativas. Analisando os códigos por meio dos princípios do design de superfície, este trabalho procura, entre outras coisas, compreender a influência dos princípios do design generativo na busca de soluções criativas para o desenvolvimento de superfícies têxteis de trama e estamparia. Nesse contexto, a pesquisa propõe também estabelecer as bases conceituais necessárias para a realização de algoritmos e, consequentemente, as lógicas de programação para a concepção de padrões complexos. 


\section{O pensamento computacional no design}

O designer, enquanto agente criativo, tem seus limites imaginativos expandidos no ambiente virtual com o crescimento da alfabetização digital por meio de linguagens de programação e da consequente absorção do pensamento computacional no desenvolvimento do projeto.

Nesse sentido, a simulação cada vez mais precisa da realidade complexa em espaço virtual se faz necessária com o avanço das tecnologias contemporâneas de fabricação digital, que cada vez mais permitem que a complexidade visualizada digitalmente possa ser transferida para a realidade por meio de métodos como a impressão 3D ou a impressão digital em tecidos. Desta forma, contribuindo para o entendimento de que o desenvolvimento do software é também uma prática cultural, Levy (1995) levanta a hipótese de que "a simulação não remete a qualquer pretensa irrealidade do saber ou da relação com o mundo, mas antes a um aumento dos poderes da imaginação e da intuição".

O uso da programação como ferramenta artística é algo que se baseia na experimentação. Por meio de códigos programados é possível criar, manipular e controlar a complexidade de objetos digitais, assim como prever estratégias de fabricação desde as primeiras etapas de criação. Woodbury (2010) constata que os computadores e a modelagem paramétrica permitem aos designers a construção de formas complexas com maior controle e precisão.

Entretanto, mais do que uma simples característica a ser esperada, a complexidade atribuída aos processos computacionais e aos resultados gráficos obtidos se refere aos conceitos envolvidos na Teoria da Complexidade tais como os sistemas adaptativos e não-lineares, a auto-organização e a teoria das redes. Estes princípios fundamentam a característica da complexidade ao permitir um controle do sistema onde a organização emerge de maneira imprevisível por meio da interação entre seus elementos.

A capacidade de gerar complexidade e emergência está relacionada com as propriedades do sistema criado em se construir, se manter e se organizar por conta própria a partir das funções e dos objetos estabelecidos (McCormack; Dorin; Innocent, 2004). Identificar e entender essas características essenciais do sistema é um importante passo para se desenvolver um projeto de design generativo.

\section{Superfícies no contexto do design generativo}

A proposta do design generativo está em descobrir, por meio de algoritmos, as relações e regras que influenciam os objetos, e aplicar as mesmas para gerar produtos de design que sejam capazes de se desenvolver e promover diferentes performances, trazendo novos conceitos para o campo do design e ampliando o catálogo de ferramentas disponíveis. (KHABAZI, 2012)

Mais do que isso, o design generativo prevê a inserção na computação dos princípios dos sistemas complexos da natureza, como a emergência e a auto-organização, combinando códigos programados com processos naturais para a geração de imagens e animações com características de complexidade. Onde elementos simples são combinados entre si por regras estabelecidas pela programação, gerando sistemas complexos onde a organização e interação dos elementos ocorre de maneira fluída, inteligente e muitas vezes, imprevisível. Deste modo, um sistema de design generativo está associado não apenas com o design paramétrico, como também com os princípios da inteligência artificial. 
O desenvolvimento do design generativo prevê ao designer a habilidade cognitiva de pensar algoritmicamente e saber lidar com princípios de lógica e programação. A função do designer está em estabelecer uma metodologia onde ocorra a definição do problema, a constituição dos conceitos abordados, a determinação das variáveis e a construção das etapas a serem executadas pelo algoritmo, independente das soluções a serem oferecidas no final pelo programa. Nesse contexto, os dados inseridos serão os parâmetros que irão seguir as regras estabelecidas e gerar os diferentes resultados possíveis de serem obtidos, dos quais o designer tem pouca ou nenhuma influência sobre eles.

O design de superfície pode se beneficiar destes novos processos criativos permitidos pelo uso da programação, seja em tecidos impressos por estamparia, em padronagens digitais ou em objetos tridimensionais confeccionados por impressão 3D.

No caso da estamparia, por exemplo, Russell (2014) afirma que as tecnologias digitais para o design generativo podem aportar modelos que se alteram em tempo real de impressão enquanto mantém as propriedades de padronagem, sem nunca se repetir. $O$ autor exemplifica que métodos matemáticos baseados em autómatos celulares permitem a evolução dos elementos de um sistema por meio da alteração de suas relações. Desta forma, ocorre a criação de padrões gráficos emergentes que se modificam com o tempo e permitem uma personalização e customização à produtos têxteis impressos, trazendo um aprimoramento ao processo de design.

Para tanto, é possível identificar que o design generativo possibilita que o projeto de design seja, não apenas inovador e criativo, como de customização de massa. O sistema complexo permite que o designer estabeleça uma relação mais fortalecida com o usuário, a partir do momento em que o mesmo tem a possibilidade de interagir com o programa previamente construído pelo designer e influenciar nos resultados finais. Com isso o consumidor tem experiências interativas com o desenvolvimento do produto e contribui também com a inserção de dados - parâmetros no código criado.

Esses novos métodos oportunizam que as estampas deixem de ser estáticas e passem a ser também imagens dinâmicas, se alterando e evoluindo progressivamente. A impressão digital do tecido será a tecnologia que irá acompanhar as mudanças da imagem digital, salvando cada seção de maneira contínua e permitindo uma padronagem sem restrições de comprimento com qualidade e variedade de cores.

Assim, Russell (2014) levanta o questionamento de se considerar o design generativo como fundamento significativo no projeto de design de superfícies estampadas do futuro, de modo que as padronagens apresentem características de infinidade, não linearidade e imprevisibilidade.

\section{Construindo padrões}

Uma das condições mais comuns no design de superfícies é a composição de padrões de repetição. Nesse sentido, a fim de identificar as metodologias utilizadas para a criação destes padrões com linguagens de programação, são apresentados a seguir os conceitos envolvidos no processo de design de superfícies como um todo.

\subsection{Fundamentação}

O termo "padrão" - ou pattern no inglês - representa um sistema de organização e implica em um design composto por uma ou mais unidades multiplicadas e arranjadas em uma sequência 
organizada sobre uma superfície (CHRISTIE, 2013). Assim, por definição, um padrão é o resultado da repetição de um elemento de maneira contínua (PROCTOR, 1990). Dentro de um sistema uniforme os módulos se repetem de modo a criarem uma textura, podendo esta ser visual ou tátil, e essa repetição pode ocorrer de diferentes formas dependendo do tipo do módulo estabelecido.

Para Wiener (apud TOUSSAINT; TOUSSAINT, 2014), um dos aspectos mais interessantes do mundo é o de ser todo constituído de padrões. Padrões estão presentes ao nosso redor, não apenas na natureza e no meio ambiente que nos rodeia, como em nosso próprio ser. (MACNAB, 2012).

Um padrão não tem apenas uso decorativo, mas também aplicações funcionais. As padronagens e possíveis texturas criadas podem apresentar, assim como na natureza, além de qualidades estéticas, também propriedades físicas, químicas e funcionais. Mais do que isso, os padrões podem servir como meios de comunicação e sentido, transmitindo mensagens culturais e sociais.

É possível classificar padrões entre tipos regulares e irregulares, sendo os regulares baseados em repetição de unidades com medida, e os irregulares baseados em aleatoriedade e repetição nãomensurável (PROCTOR, 1990). O método de criação de padrões de repetição regulares pode servir como fundamentação para o desenvolvimento de padrões de repetição irregulares, ou seja, onde a repetição não pode ser prevista ou controlada. Desta forma, entender as bases conceituais da composição de padrões é o primeiro passo para se atingir superfícies visuais complexas.

Nesse contexto, a composição gráfica de uma padronagem pode ocorrer de duas maneiras: pela estrutura da construção do grid como mostra a Figura 1; e pelo modo como o módulo (elemento/unidade) se movimenta dentro deste, conforme a Figura 2 que foi criada com base no que determina Evelise Ruthschilling em seu livro ‘Design de Superfície' (RÜTHSCHILLING, 2008).

Figura 1 - Tipos de estruturas de repetição

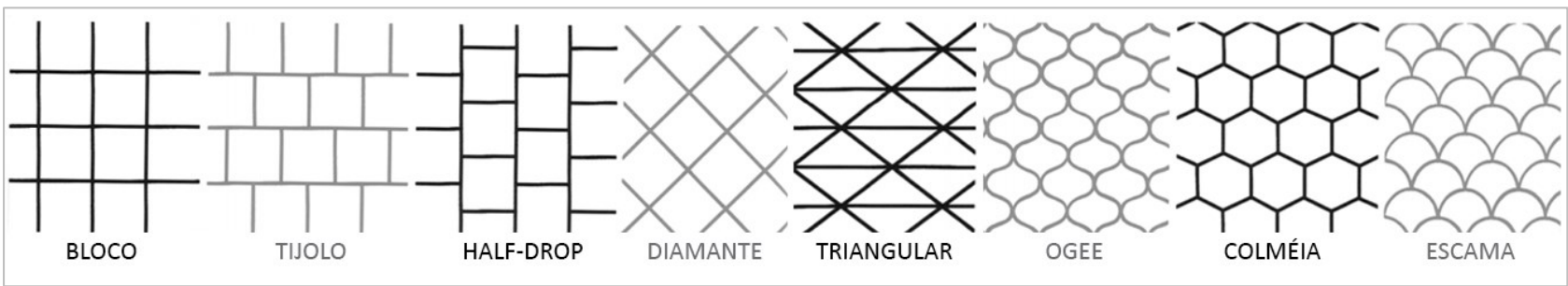

Fonte: o autor (2018)

Figura 2 - Modo de organização do módulo em um bloco de repetição

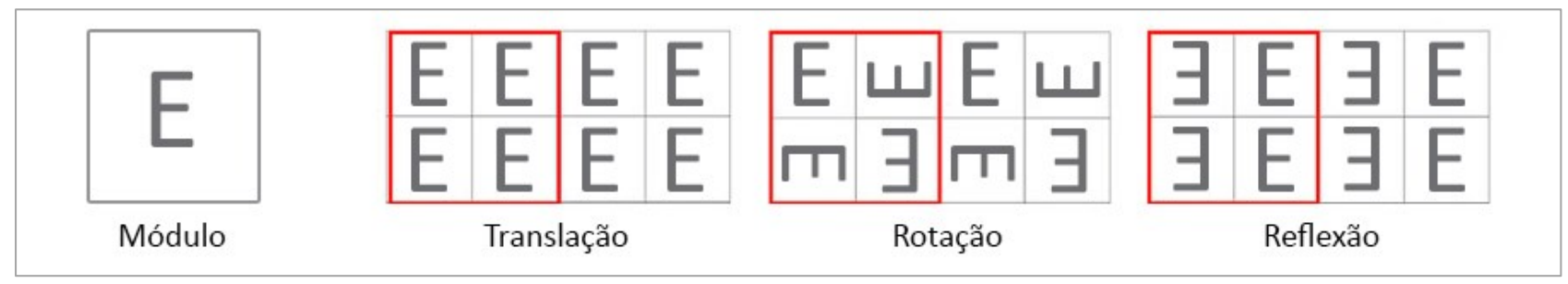

Fonte: o autor (2018) 
Cabe ao designer a tarefa de determinar o tipo de repetição escolhida e a maneira como o módulo criado irá se repetir dentro desta organização pré-estabelecida. Essas propriedades serão definidas de acordo com os objetivos e o local de aplicação da superfície visual criada.

Para McWilliams e Casey Reas todos os padrões visuais são em sua essência composições algorítmicas e podem, portanto, ser trabalhados por meio de linguagens de programação como o Processing:

Padrões repetitivos são usados extensivamente para aplicações que exigem a ilusão de uma imagem contínua, como têxteis e papéis de parede. (...) Novas tecnologias de prototipagem rápida e equipamentos de fabricação controlados por computador tornam possível explorar ainda mais essa área (REAS; MCWILLIAMS, 2010, p.59).

Os autores afirmam ainda que a repetição é uma característica constante em um padrão e que tem a função de fornecer ritmo às formas. Nesse sentido, repetir elementos e organizá-los em uma composição visual pode ser uma maneira muito interessante também de tornar as superfícies digitais, não apenas em imagens estáticas, mas em vídeos e animações interativas.

\subsection{Estado da Arte}

Devido à intensa rede de colaboração e troca de informações que o software Processing disponibiliza, muitos dos algoritmos possuem código aberto e permitem que os usuários reutilizem o código de outra pessoa, fazendo modificações para melhorar a sua estrutura e organização, reduzindo e otimizando o conteúdo. Também podem ser feitas alterações de ordem estética e funcional, além da manutenção e aprimoramento da lógica e matemática envolvidas para atender uma determinada demanda criativa.

Utilizando como base para o design de superfície, foram escolhidos dois exemplos de códigos disponíveis no grupo colaborativo online 'OpenProcessing.org'. O primeiro, conhecido como Maze, estabelece uma estrutura de grid em bloco onde um único elemento - uma linha diagonal - é aleatoriamente movimentado seguindo os princípios mencionados de translação e reflexão. A randomização programada do módulo permite a representação de um labirinto onde o padrão de repetição é imprevisível e nunca é o mesmo.

Figura 3 - Algoritmo do Processing para desenvolvimento de grid de repetição

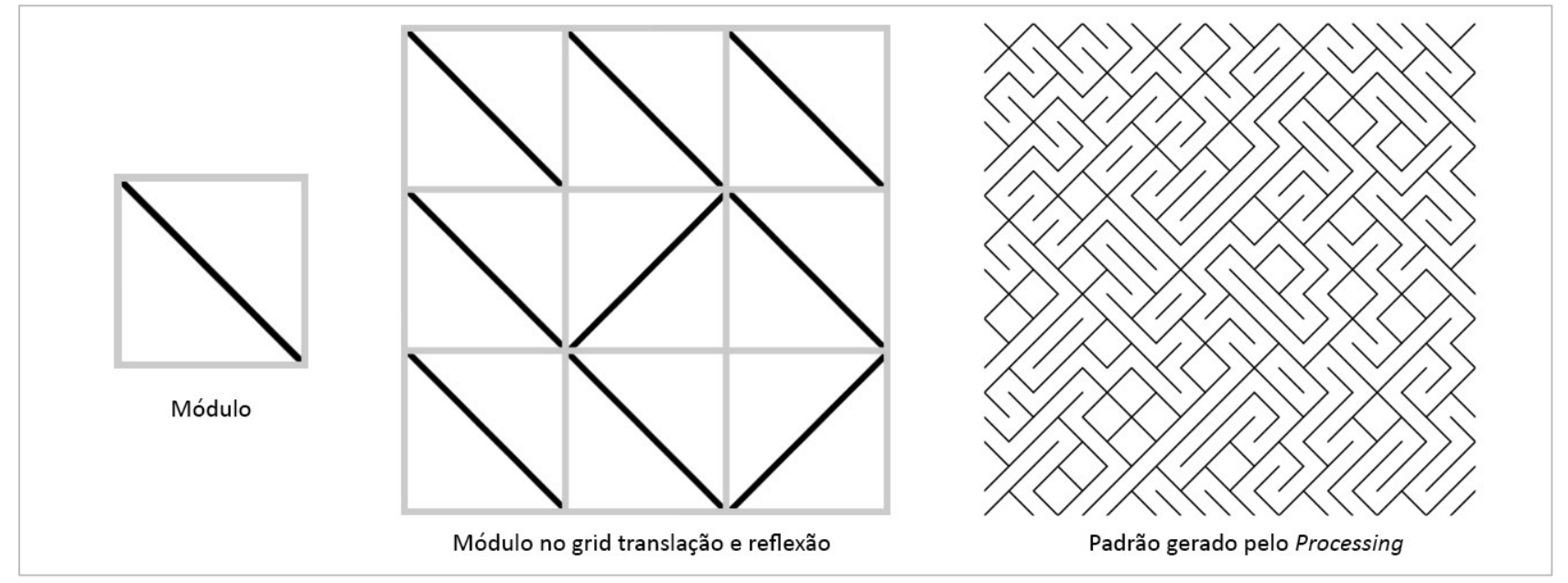

Fonte: openprocessing.org (2018) 
Ainda no que diz respeito à códigos abertos de padronagens, o exemplo da Figura 4 utiliza dois módulos diferentes para a composição do padrão, e o princípio de repetição é de rotação. $A$ escolha e disposição destes, assim como na Figura 3, são randômicas e, por isso, impossibilitam a previsão do resultado final obtido. A cada execução do algoritmo, uma composição visual diferente será apresentada.

Figura 4 - Algoritmo do Processing para desenvolvimento de grid de repetição

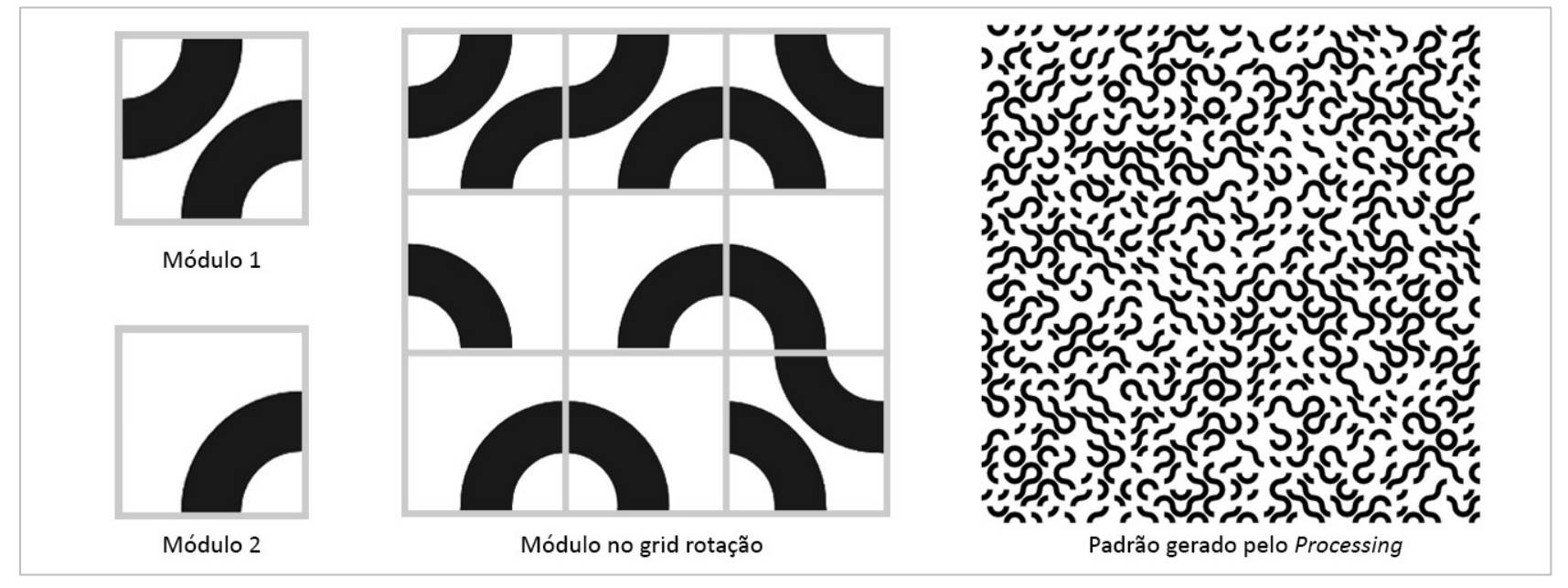

Fonte: o autor (2018)

Os dois exemplos escolhidos (Figuras 3 e 4) mostram códigos diferentes com os mesmos princípios lógicos de repetição de um módulo em um grid de bloco. Ao serem definidas as regras de organização dos elementos inseridos e as características estéticas destes, fica a cabo do software a realização da composição visual final. Desta forma, como em todo design paramétrico, o designer se responsabiliza principalmente pela inserção dos parâmetros, sem ter controle direto da representação que irá emergir como resultado do código.

Nos dois casos apresentados, apesar de terem uma estrutura lógica mais simples, seria possível alterar aspectos estéticos do módulo, como a cor e a espessura das linhas ou as propriedades do fundo da tela. Essas alterações poderiam ser fixas ou variáveis, dependendo do propósito do artista-programador. Haveria também a possibilidade de que os módulos fossem aparecendo aos poucos e a organização destes emergindo conforme regras estabelecidas previamente.

Para entender melhor como estruturar um grid de repetição no ambiente do Processing, é preciso a aquisição de princípios de lógica e conhecimento básico da sintaxe da linguagem de programação. Vale lembrar também que todas as instruções apresentadas no software são em inglês.

\subsection{Desenvolvimento de padrão}

Buscando assimilar os princípios necessários para a formulação de um grid, foi criado um código base onde, posteriormente, pudesse ser desenvolvida uma padronagem qualquer.

Como visto, existem inúmeras maneiras de se realizar a composição de um padrão e, consequentemente, diferentes lógicas de programação para tal finalidade. Não existe uma regra específica e a criatividade fica por conta do designer, ou artista-programador. Tudo irá depender 
dos objetivos desejados e do nível de conhecimento do responsável pelo código. Por isso é tão significativo que o designer tenha, não apenas conhecimento da linguagem de programação utilizada, como também noções básicas do design de superfícies repetidas.

Para se estruturar um grid de repetição, a construção de uma grade quadriculada é, possivelmente, a mais simples. A lógica envolvida em um design de superfície de repetição deve acompanhar a organização de um módulo no espaço, e neste caso o método escolhido foi a repetição tipo bloco de um retângulo que, ao se repetir, formará uma estrutura.

Esse código simples foi criado para dar fundamentação aos conhecimentos necessários para o desenvolvimento de estruturas e funções mais complexas. É preciso entender e representar primeiro o modo mais simples para conseguir evoluir gradativamente a maneira como o código é programado e como as relações entre os elementos se intensificam.

A repetição ocorre em uma composição de linhas e colunas que se intercalam, instituindo uma trama. O princípio é básico, para cada coluna, se insere uma nova linha até se atingir o tamanho desejado. E dentro dessa sequência é que serão inseridos os elementos a serem repetidos, neste caso o retângulo através da função do Processing 'rect' (Figura 5).

Figura 5 - Algoritmo do Processing para desenvolvimento de grid de repetição

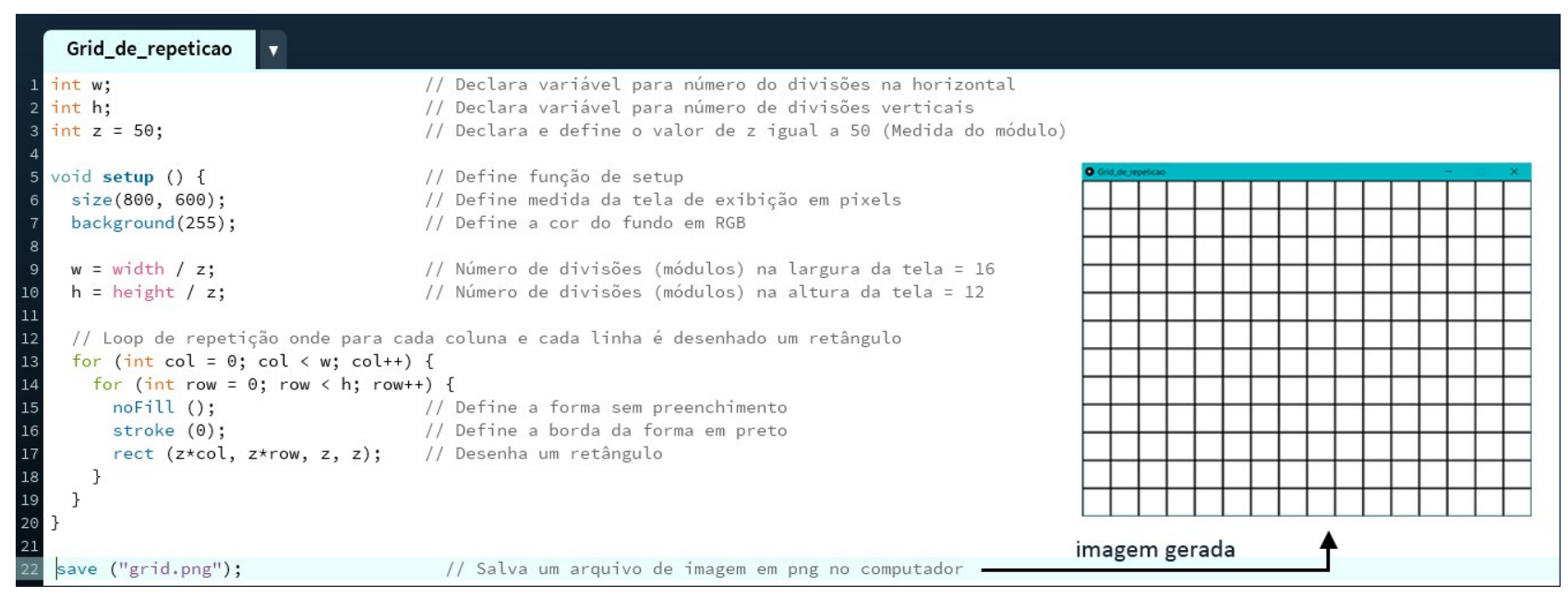

Fonte: o autor (2018)

No algoritmo apresentado (Figura 5) observa-se inicialmente a declaração das variáveis utilizadas no código ( $w, h, z)$. Depois, são definidos parâmetros gerais referentes aos elementos essenciais da composição visual, sendo estes o tamanho (size) e a cor da janela (background) onde será inserida a representação visual.

Em seguida, foi criado um loop de repetição seguindo o princípio de colunas (col) e linhas (row) onde se inserem os módulos. Os elementos a serem inseridos e repetidos podem ser de ordem geométrica como pontos, linhas, elipses e outros, mas nada impede que se utilizem também imagens prontas ou composições mais complexas. Uma vez que a lógica de construção seja instituída, os elementos desenhados podem ser alterados pelo próprio artista-programador quantas vezes quiser. Isso amplia o cenário criativo e os resultados visuais obtidos.

Desta maneira, se os parâmetros estiverem inseridos dentro de variáveis, essas variáveis 
podem ser alteradas manualmente ou por funções programadas como a interação de um usuário, a inserção de dados externos ou o uso da ferramenta de randomização, por exemplo.

Nesse sentido, a aleatoriedade tratada no software pelo termo em inglês 'random' é uma propriedade muito significativa para a construção de padrões variados e complexos. A randomização pode ser incluída em todos os parâmetros utilizados, seja na cor, no tamanho, na posição ou até na escolha do próprio objeto de repetição. Isso retira do programador o controle e permite o surgimento de superfícies gráficas variadas e imprevisíveis, ou seja, uma arte gerada por um processo completamente randômico pode facilmente gerar padrões altamente estruturados (TOUISSANT; TOUISSANT, 2014).

Assim, as características estéticas e formais dos objetos a serem inseridos como cor, preenchimento, borda, entre outras, podem se alterar sem que a estrutura do código seja abalada.

O estúdio WOVNS, empresa responsável pelo desenvolvimento de tecidos tramados, disponibiliza uma base de exemplos de Processing gratuita em seu site oficial. Os tutoriais oferecidos permitem ao consumidor editar e alterar algoritmos de padrões de repetição de modo a customizar o produto têxtil que se deseja adquirir. Desta forma, é possível fazer o download gratuito de um pacote com 18 exemplos de códigos abertos e escolher qual algoritmo se deseja trabalhar para, futuramente, comprar o tecido pelo site.

Na Figura 6 é possível verificar o resultado de um exemplo criado pela Wovns que alia a lógica de grid com princípios de randomização. A imagem representada mostra a padronagem criada e sua execução enquanto produto têxtil. Diferentemente de uma estamparia pintada, o tecido em questão tem os padrões como parte integral da trama estabelecida.

\section{Figura 6 - Tecido tramado com padrão desenvolvido no Processing}

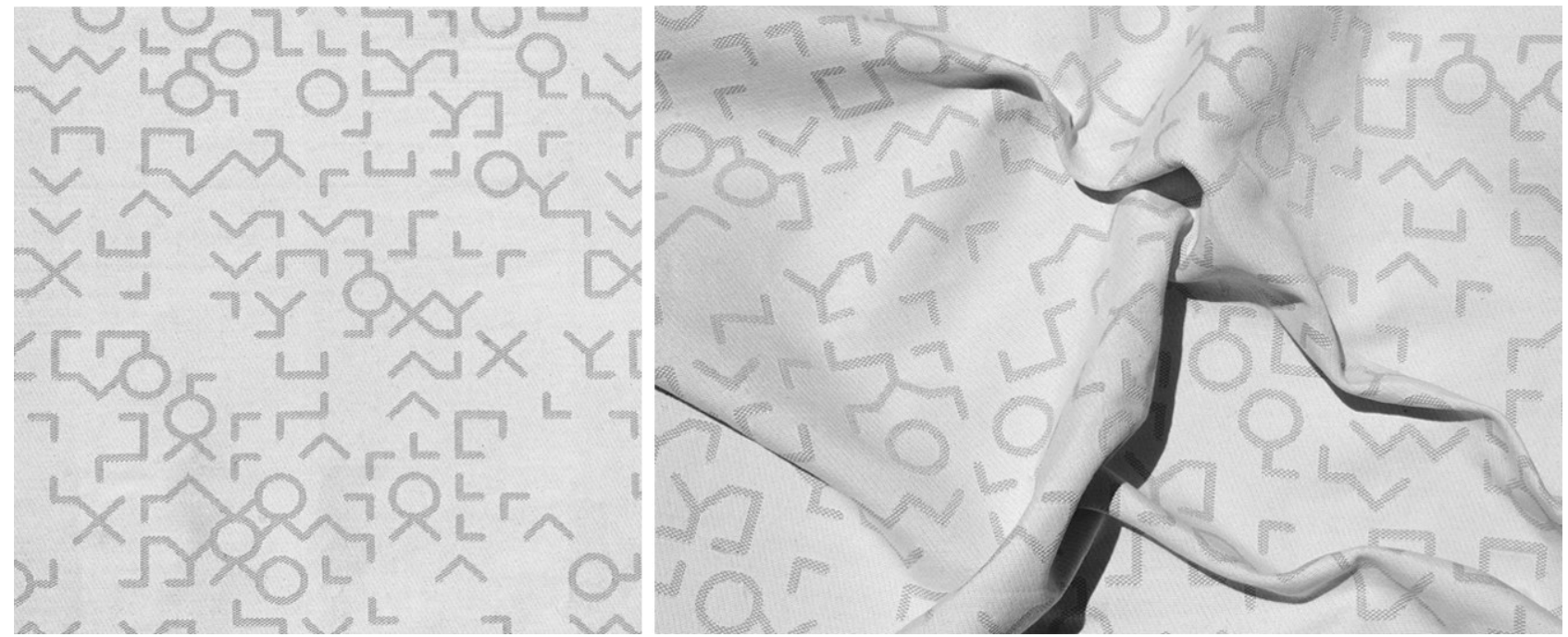

Fonte: wovns.com (2018)

A complexidade emerge da maneira como os módulos interagem entre si e dos resultados visuais obtidos. $O$ cliente pode personalizar seu produto e alterar completamente a trama escolhida. A quesito de exemplo, foram feitas algumas alterações no código aberto da estampa mencionada.

A lógica proposta no script determina a construção de grid em formato de bloco igual à 
mencionada anteriormente no código da Figura 5. Para o padrão da WOVNS estão estabelecidos 7 tipos de módulos que variam entre linhas e elipses. A exibição ou não destes elementos é escolhida de maneira aleatória por meio de uma condicional que seleciona um número randômico entre $0 \mathrm{e}$ 7, sendo 0 a não exibição de módulos.

Seguindo esse mesmo código e as mesmas regras, foram criados 7 módulos novos (Figura 7). Ao substituir os módulos anteriores pelos novos, obteve-se uma padronagem completamente diferente sem que fosse necessária a reprogramação dos demais dados no Processing. A propriedade da randomização permite que a padronagem final gerada se altere a cada execução do programa.

Figura 7 - Padrão randômico criado com o código aberto do estúdio WOVNS

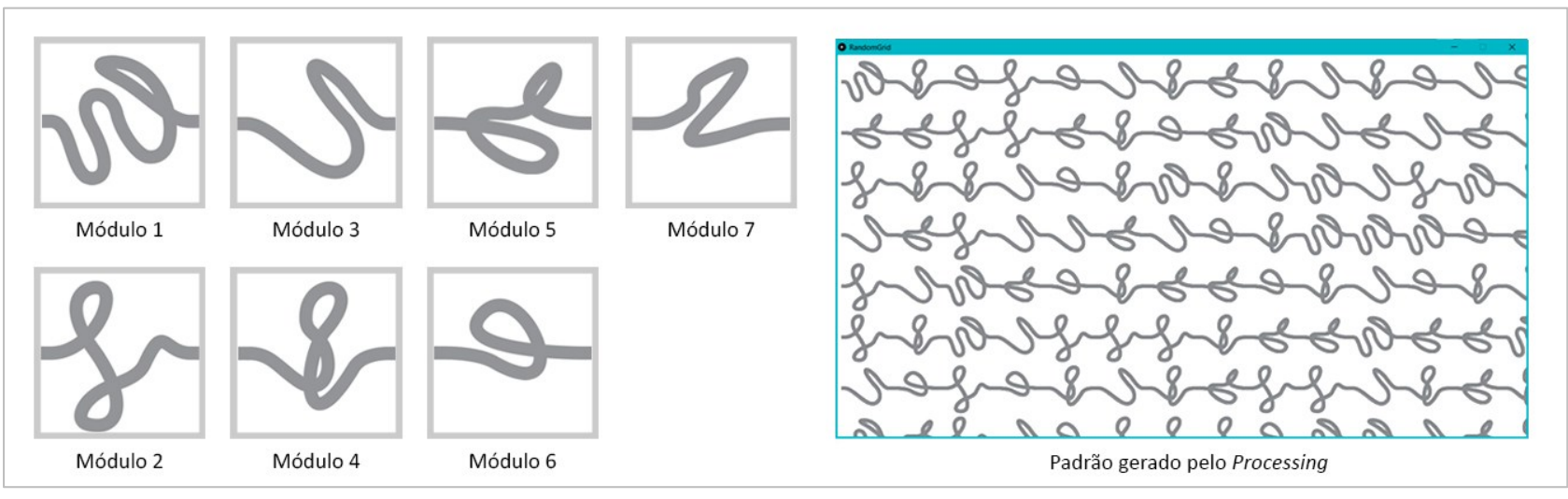

Fonte: o autor (2018)

As mudanças poderiam ocorrer também na cor do fundo ou em outras propriedades estéticas da composição. Além disso, a função de randomização poderia ser substituída por outro tipo de condição ou regra que determinasse a exibição dos módulos de maneira imprevisível.

Com isso, observa-se que no caso do código programado em um algoritmo computacional, a liberdade de determinar e alterar funções e objetos disponibiliza uma ampla gama de possibilidades criativas e de resultados estéticos diferenciados. Assim, um único código programado é capaz de gerar uma infinidade de composições visuais.

\section{Considerações Finais}

As padronagens ocupam espaço em muitas áreas de aplicação do design, como em tecidos estampados, papéis de parede, azulejos e artigos de papelaria, por exemplo. Pela sua presença e notoriedade dentro do design de superfícies, o desenvolvimento de padrões faz parte dos conhecimentos essenciais e necessários ao designer deste campo de projeto. Nesta pesquisa, foi significativo destacar a importância do envolvimento de uma metodologia de design específica para a realização de padrões de repetição e, por consequência, na compreensão por parte do designer dos processos envolvidos.

Nesse contexto, foi identificado o papel do designer frente às novas tecnologias digitais. $\mathrm{O}$ profissional deve buscar complementar sua formação para realizar uma alfabetização digital com relação à novas linguagens de programação voltadas ao design e às artes, como é o caso do Processing. Assim, a abrangência criativa envolvida na atividade da programação de dados pode 
trazer grandes perspectivas para a atividade do design complexo, permitindo uma valorização nos princípios referentes a realização de códigos para a construção de superfícies com diversos níveis de complexidade.

A pesquisa proporcionou o entendimento de uma evolução funcional e estética em códigos abertos que podem ser alterados e transformados de modo que uma mesma função de criação de padrão possa variar de acordo com os propósitos e as aplicações da superfície. Para superfícies digitais e interativas, o uso de algoritmos generativos e evolutivos pode se apresentar de modo muito inovador, principalmente quando se levantam questões como a interação com o usuário ou a entrada de dados aleatórios, sustentados pelos princípios de emergência da forma e organização adaptativa dos elementos do sistema visual.

De modo geral, o objetivo principal foi entender os princípios básicos para se criar um algoritmo com enfoque no desenvolvimento de padrões de repetição e, assim, visualizar o modo mais simples de se programar o código e estabelecer precedente para algoritmos cada vez mais complexos. Com isso, designers com pouco ou nenhum conhecimento de programação podem expandir sua capacidade intelectual e compreender os princípios lógicos envolvidos em um algoritmo programado.

O foco no uso das novas tecnologias deve estar em encontrar os benefícios que estas apresentam quando comparadas com técnicas tradicionais. Alguns destes benefícios podem ser referentes à melhora do processo de projeto e, consequentemente, no trabalho do designer. As possibilidades criativas e diferenciadas que as linguagens de programação proporcionam para o design podem influenciar significativamente nas etapas de criação e execução da composição visual. A otimização e variedade dos resultados, obtidos por meio de algoritmos computacionais, também devem ser levadas em conta. Além disso, o projetista pode se beneficiar de uma possível diminuição da carga de trabalho e a possibilidade de uma grande quantidade de imagens esteticamente diferenciadas.

Por fim, vale destacar que o aspecto colaborativo do Processing abre uma porta de possibilidades para os designers e artistas-programadores que estão iniciando nesse meio de linguagens de programação, e consequentemente, auxilia no condicionamento destes profissionais permitindo, muitas vezes, que o foco da criação seja mais no lado criativo e estético do projeto do que no lado lógico e matemático envolvido.

\section{Referências}

ALEXENBERG, Melvin L. The Future of Art in a Postdigital Age: From Hellenistic to Hebraic Consciousness. Chicago: Intellect Books, 2011.

BOZOLAN, Sandra M. O pensamento computacional: ensino e aprendizagem através do software Processing. 2016. Dissertação (Mestrado em Tecnologias da Inteligência e Design Digital) Pontifícia Universidade Católica de São Paulo - PUC, São Paulo.

CHRISTIE, Archibald H. Pattern Design: An introduction to the study of formal ornament. Courier Corporation: New York, 2013.

KHABAZI, Zubin Mohamad. Generative algorithms: Using Grasshopper. E-book. Disponível em: <www.morphogenesism.com>, USA, 2012

LÉVY, Pierre. As tecnologias da inteligência: o futuro do pensamento na era da informática. São 
Paulo: Editora 34, 1995.

MACNAB, Maggie. Design by Nature - Using universal forms and principles in design. New Riders: Canada, 2012.

MCCORMACK, Jon; DORIN, Alan; INNOCENT, Troy. Generative design: a paradigm for design research. In: Redmond, J. et. al. (eds) Proceedings of Futureground, Design Research Society, Melbourne, 2004.

MELLO, Patricia Oakim Bandeira de Mello. Arte e programação na linguagem Processing. 2015. Dissertação (Mestrado em Tecnologias da Inteligência e Design Digital) - Pontifícia Universidade Católica de São Paulo - PUC, São Paulo.

PROCTOR, Richard M. Principles of Pattern Design. Dover Publications: New York, 1990.

REAS, Casey; MCWILLIAMS, Chandler. Form + code in design, art, and architecture. Nova York: Princeton Architectural Press, 2010.

RUSSELL, Alex. Repeatless: transforming surface pattern with generative design. In: Shapeshifting Conference: Auckland University of Technology, Nova Zelândia, 2014.

RÜTHSCHILLING, Evelise Anicet. Design de superfície. Porto Alegre: Ed. da UFRGS, 2008.

TOUSSAINT, Eva R; TOUSSAINT, Godfried T. What is pattern? In: Proceedings of Bridges 2014: Mathematics, Music, Art, Architecture, Culture. Seoul, Korea. 2014

WOODBURY, Robert. Elements of parametric design. Routledge, Taylor \& Francis Group. New York, 2010

\section{Agradecimentos}

Os autores agradecem a FAPESP (Processo 2017/07647-0) pelo apoio financeiro. 